\title{
Open fractures of Tibia treated by unreamed interlocking nailing
}

\author{
Nirmal Chandra Mohapatra ${ }^{1}$, Udit Saurav Sahoo ${ }^{1}$
}

\section{Abstract}

Objective: To assess the clinical outcome of unreamed intramedullary interlocking nailing in open fractures of tibia, and to evaluate the incidence of complications in these open fractures as a result of the same.

Methods: Between June 2018 and May 2019, a total of 56 cases of open tibial shaft fractures were operated on with unreamed interlocking nails at SCB MCH, Cuttack, India. Records of 52 patients (18 women and 34 men) were available for study. Only injuries associated with the tibial shaft were included. Traffic accidents were the cause of fractures. All fractures were classified according to Gustilo and Anderson classification for open fractures. There were 28(53.8\%) type-I, 16 (30.7\%) type-II, 8 (15.3\%) type- IIIA fractures. After thorough debridement under anaesthesia, an unreamed interlocking nail was inserted. All nails were locked proximally and distally.

Results: The patients were followed up for a mean period of 19 months (range, 18-24 months) and were evaluated according to the modified Ketenjian's criteria. Results were good to excellent in $85.8 \%$ cases, and poor in $10.7 \%$ cases. Only 2 of 8 patients with type-III fractures had good results. Of 56 patients, 6 had superficial infection, 4 had deep infection, 6 had delayed union, 1 had infected non-union, 3 had malunion, 6 had screw breakage, and 10 had anterior knee pain.

Conclusion: Unreamed interlocking tibial nailing can be safely used for type-I and type-II open injuries even with delayed presentation. Use of unreamed nailing in type-III fractures with delayed presentation has high incidence of complications in this study.

Keywords: Unreamed interlocking nail, Open tibial fractures.

\section{Introduction}

Tibia is one of the most common bones to sustain open injury because of its superficial nature. The number of complex trauma cases caused by traffic accidents have increased progressively in India. External fixation is associated with a high incidence of complications including pin tract infection, malunion, delayed union and nonunion $[1,2]$. Early debridement and unreamed interlocking nailing have emerged as important modalities for the management of open fractures of tibia. However, since many cases in our country are presented late to the emergency department with improper initial management, our results of the management of open fractures are likely to be different from those reported in the western literature. We studied the clinical outcomes of unreamed intramedullary interlocking nailing in 52 cases of solely compound fractures of tibia.

\section{Methods}

Between June 2018 and May 2019, a total of 56 cases of open tibial shaft fractures were operated on with unreamed interlocking nails. 4 patients were lost to follow-up. 52 patients ( 18 women and 34 men)

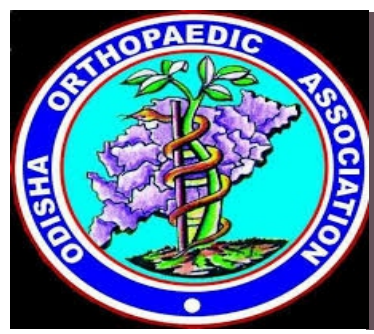

${ }^{1}$ Department of Orthopaedics, SCB Medical

College, Cuttack, Odisha, India.

Address of Correspondence

Dr. Udit Sourav Sahoo

SCB Medical College, Cuttack, Odisha, India.

E-mail: uditsouravsahoo@gmail.com were followed up for a mean period of 20 months (range, 18-24 months). Only injuries associated with the tibial shaft were included. Type-III c fractures, fractures associated with head injury, chest injury, major neurovascular injury, proximal tibial shaft articular fractures, and fractures within $5 \mathrm{~cm}$ of distal articular surface of tibia were excluded.

Traffic accidents were the cause of fractures in all patients. The patients' median age was 30 years (range, 16-62 years). The morphology of all fractures was classified according to the classification of Gustilo and Anderson [4] for open fractures. There were 28 (53.8\%) type-I, 16 (30.7\%) type-II, 8 (15.3\%) type-III. 38 fractures were at mid-shaft level and 14 fractures were at the positions of either the upper one third or the lower one third of the tibia. In all the cases, injectable third-generation cephalosporins and aminoglycosides was started in the emergency room and kept using them after surgery for 1 week and 5 days, respectively. In cases of contamination, metronidazole was added. Wounds were irrigated with normal saline (7-10). After thorough debridement under anaesthesia, unreamed interlocking nail (size 8 in 43 cases and size 9 in 9 cases) was inserted under image intensifier guidance. All the nails were locked with bolts proximally and distally.

46 of the 56 cases $(88.4 \%)$ presented to emergency department within 24 hours of injury; however, $78 \%$ of them were operated after 24 hours of injury because of delay in setup. Only 10 cases presented after 24 hours ( 4 cases of type IIIA). The mean operating time was one hour (range, 45- 90 minutes). Mean interval from injury to operation was 34 hours (range, 8-48 hours). Wounds were re-

(C) 2020 by Authors | Available on www.ojotonline.com | DOI: 10.13107/ojot.2020.v41i01.003

This is an Open Access article distributed under the terms of the Creative Commons Attribution Non-Commercial License (http://creativecommons.org/licenses/by-nc/3.0) which permits unrestricted non-commercial use, distribution, and reproduction in any medium, provided the original work is properly cited. 


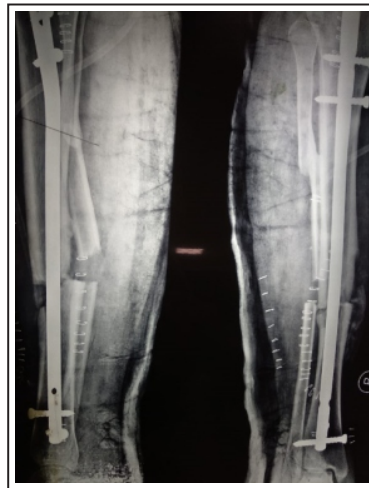

Fig. 1 a: Non Union on Subsequent follow up

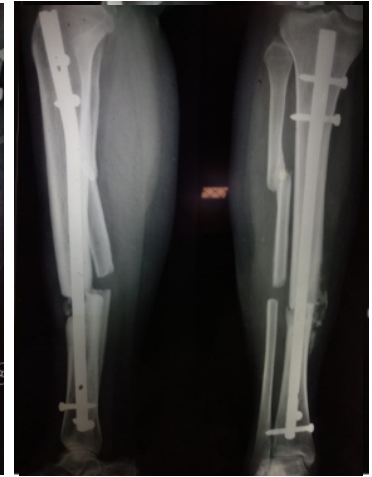

Fig. 1 b: Union on subsequent follow up

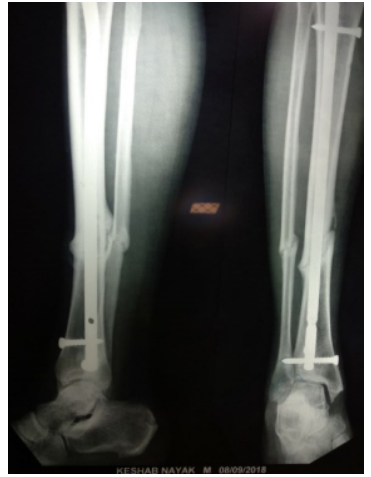

Fig. 2 a: Delayed union

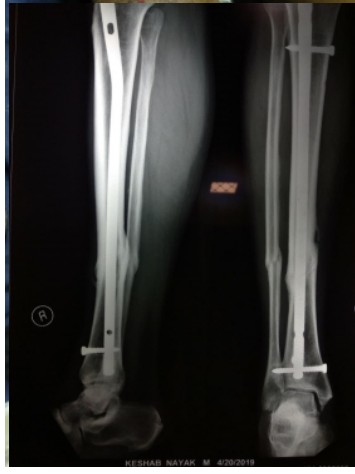

Fig. 2 b: Union on subsequent follow up

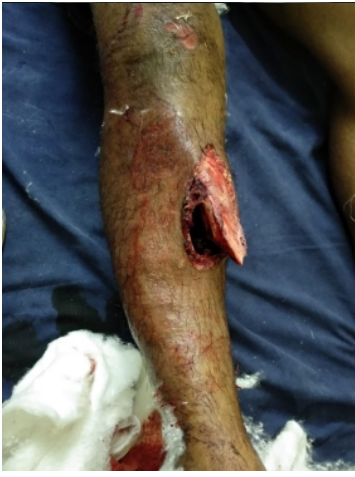

Fig. 2 c: Intra op picture

examined after 24 hours and further debridements were planned accordingly. Primary wound closure was performed in 14 cases. Muscle flaps and fasciocutaneous flaps were used to cover the exposed bone on postoperative day 7-10. Early postoperative mobilisation was encouraged, when not contraindicated by other injuries.

Cases were followed up regularly and were evaluated functionally according to modified Ketenjian's criteria. X-rays were taken at regular intervals, and weight bearing was allowed based on radiological evidence of callus formation. Of 56 cases, 40 (71.4\%) cases required only one debridement, $10(17.9 \%)$ required 2 debridements ( 8 in type II and 2 in type IIIA), and $6(10.7 \%)$ required 3 debridements (4 in type IIIa, 2 in type IIIb). The mode of soft tissue coverage is shown in Table 2.

Delayed union was defined as lack of union 6 months postoperatively. Radiographic evidence of union was defined by the presence of bridging callus, and clinical union by the ability to support body weight unaided without pain. Superficial infection was defined as local erythema which resolved with antibiotic therapy. Deep infection was defined as continuing wound drainage or a positive bacteriological culture. Statistical analysis (SPSS) was used to evaluate the rate of union and the incidence of infection according to grade, type and site of fracture.

\section{Results}

The mean follow-up was 19 months with a minimum of 11 months. 43 fractures united within 6 months with a mean period to union of 26.2 weeks. There were 3 nonunions, treated with bone grafting ( fig. 1a, 1b), and 6 cases in which union was delayed for more than 6 months and 2 were dynamised by removing the proximal screw; rest 4 united

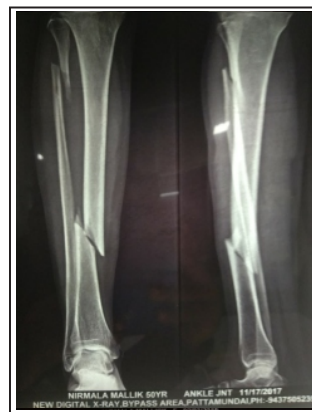

Fig. 3 a: Pre op xray

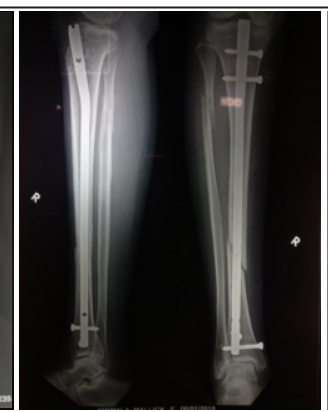

Fig. 3 b: Delay in union

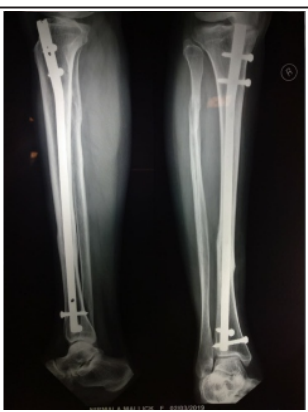

Fig. 3 c: Complete union on subsequent follow up on subsequent follow ups (Fig. 2a,2b,3a,3b,3c). According to the severity of grade, the mean time to union of grade I fractures was 22.8 weeks, that of grade II fractures was 26.3 weeks and grade III fractures at 29.8 week. There was thus no statistically significant correlation between severity of the open fracture and the time to union in this study (Table 2). The mean time to union according to the AO classification was 18.2 weeks with type A fractures, 23.6 weeks with type B fractures and 29.3 weeks with type $C$ fractures (Table 2). Thus the union time was longer in more complex high energy fractures $(\mathrm{P}=0.02)$. The mean non-weightbearing period was 8.2 weeks (range, 6-14 weeks) and the mean partial weight bearing period was 7.3 weeks (range, 6-20 weeks).

There were 6 superficial infections, 2 in a grade II fracture and 4 in a grade IIIb fracture, successfully treated with antibiotic therapy. There were 4 deep infection, all associated with a grade IIIb fracture, 3 of those resolved after serial debridement and antibiotic treatment. 1 case (type IIIB) progressed to infected non-union with discharging sinuses and had intermittent flares of acute osteomyelitis; as a result, the nail was removed at 36 weeks, Ilizarov fixator was applied, and corticotomy was carried out subsequently.

There was 3 cases of malunion, defined as a rotational deformity of more than $10^{\circ}$ or an angulation deformity of more than $10^{\circ}$ or shortening by more than $10 \mathrm{~mm}$. Locking screws broke in 6 cases; no nails broke. There were no complications requiring removal of implant or amputation.

Functional results based on the modified Ketenjian's criteria are shown in Table 4. Results were good to excellent in 41 (78.8\%), fair in 7 (13.4\%), poor in 4 (7\%, all of the them had infected non-union).

\section{Discussion}

The external fixators are versatile and can facilitate early soft-tissue healing, had been extensively used. However, it is associated with a high incidence of pin tract infection, pin loosening, nonunion and late angular deformity $[3,4]$. If a secondary procedure of nailing or plating is undertaken after the removal of fixator, there will be a high incidence of infection despite adequate antibiotic coverage $[5,6,7]$. The current trend of management of Gustilo type I, II, and IIIA open fractures of tibia presented to the emergency department within 6 to 8 hours is to perform unreamed intramedullary nailing. The unreamed tibial nailing is reported to have definite advantages over the reamed nailing [8]. Unreamed nailing in experimental studies has been found to cause less reduction in cortical circulation as compared 


\begin{tabular}{|c|c|c|c|c|}
\hline \multicolumn{5}{|c|}{ Table 1: complications. } \\
\hline \multicolumn{3}{|c|}{ Complications } & $\begin{array}{l}\text { No. of } \\
\text { patients }\end{array}$ & $\begin{array}{l}\text { Percentage } \\
\%\end{array}$ \\
\hline \multicolumn{3}{|c|}{ Superficial early infection } & 6 & 11.5 \\
\hline \multicolumn{3}{|c|}{ deep infection } & 4 & 7.6 \\
\hline \multicolumn{3}{|c|}{ Screw breakage } & 6 & 11.5 \\
\hline \multicolumn{3}{|c|}{ Anterior knee pain } & 10 & 19.2 \\
\hline \multicolumn{3}{|c|}{ Delayed union } & 6 & 11.5 \\
\hline \multicolumn{3}{|c|}{ malunion } & 3 & 5.7 \\
\hline \multicolumn{5}{|c|}{$\begin{array}{l}\text { Table 2: Union time and infection according to the } \\
\text { Gustilo-Anderson classification system. }\end{array}$} \\
\hline Grade & \multicolumn{3}{|c|}{ No. of cases $(\%)$} & $\begin{array}{l}\text { Union time } \\
\text { (weeks) }\end{array}$ \\
\hline I & \multicolumn{3}{|c|}{$28(53.8)$} & 22.8 \\
\hline II & \multicolumn{3}{|c|}{$16(30.7)$} & 26.3 \\
\hline IIIA & \multicolumn{3}{|c|}{$5(9.6)$} & 28.8 \\
\hline IIIB & \multicolumn{3}{|c|}{$3(5.7)$} & 30.4 \\
\hline Total & \multicolumn{3}{|c|}{52} & 26.2 \\
\hline \multicolumn{5}{|c|}{$\begin{array}{l}\text { table 3: Union time and nonunion according to the AO } \\
\text { classification. }\end{array}$} \\
\hline \multicolumn{2}{|c|}{ Types } & \multicolumn{2}{|c|}{$\begin{array}{l}\text { No. of cases } \\
(\%)\end{array}$} & $\begin{array}{l}\text { Union time } \\
\text { (weeks) }\end{array}$ \\
\hline \multicolumn{2}{|c|}{ A (22) (simple) } & \multicolumn{2}{|c|}{$28(53.8)$} & 18.2 \\
\hline \multicolumn{2}{|c|}{ B (18) (wedge) } & \multicolumn{2}{|c|}{$18(34.6)$} & 23.6 \\
\hline \multicolumn{2}{|c|}{ C (6) (complex) } & \multicolumn{2}{|c|}{$6(11.5)$} & 29.3 \\
\hline \multicolumn{2}{|c|}{ Total } & \multicolumn{2}{|c|}{52} & 26.2 \\
\hline
\end{tabular}

to reaming of the medullary canal $[8,9]$. Klein et al. [8] reported $31 \%$ reduction of cortical circulation using unreamed nail as compared to $71 \%$ reduction after reaming. Reaming of open fractures has been found to spread the contamination from open wound along the medullary cavity and to strip small fragments of bone from the soft tissue attachment [11]. Reaming has also been reported to slow the revascularisation and delay osseous union $[9,12]$. Cortical necrosis is less likely to occur with a loosely fitted unreamed nail than a snugly fitted reamed nail [14]. In addition, smooth surface of nail may decrease the susceptibility of infection by decreasing the adherence of bacteria [15].

The majority of our patients (98\%) were operated on after 24 hours of injury because of delay in setup. One of the objectives of this study was to evaluate the incidence of complications in these open fractures treated with unreamed intramedullary nailing beyond the initial 24 hours. Despite thorough debridement and adequate soft tissue coverage, there was an overall incidence of deep infection in 4 of $52(7.6 \%)$ cases, all of which was in type-III b open fractures. Delayed management of these high-velocity typeIII injuries with extensive tissue damage and contamination exacerbates bacterial colonisation and chronic deep infection. The type-I and type-II open fractures, with comparatively less softtissue damage and contamination, can be safely managed by debridement, early wound coverage, and unreamed interlocking nailing, as shown in our study that there was no evidence of deep infection in these types of fractures. Various series reported $2 \%$ to $16 \%$ incidence of deep infection and the majority of which were type- III compound injuries $[1,2,9,14]$. The series also recommended careful selection of patients for using interlocking nail in this type of fracture. In our study, the only infected nonunion case indicates to the above findings. When significant disruption of bony vascularity was present, normal process of bony union could be hampered to a considerable extent, which was observed in our cases of delayed unions and non-unions that subsequently required bone graft supplementation. Yokoyama et al. reported a mean union time of 15 months in more than $50 \%$ of type-III fractures, whereas the overall mean union time in their series was 6.6 months, which is comparable with that in our series (26.2 weeks). Comparable incidences of delayed union and bone graft supplementation were also reported in other series $[2,4,14,15]$.

In our series, the incidence of screw breakage was $11.5 \%$, which was comparable to the $6 \%$ to $40 \%$ of that in other series $[1,7,14,15]$. Kneifel and Buckley [16] advocated to use 2 screws each for both proximal and distal locking to make the assembly rigid and reduce the incidence of screw failure. In our series, $78.8 \%$ of overall results were good to excellent. Yokoyama et al. reported that $89 \%$ of the results in type-I and type-II fractures were good to excellent, and $75 \%$ of the results in severe type-III open fractures were good. In contrast, in our series of type- III open fractures, only $25 \%$ of the results were good.

\section{Conclusion}

Adequate debridement, early soft-tissue coverage, and early adequate fixation are the key to minimise deep infection. We recommend using unreamed locked tibial nailing for type-I and type-II open fractures of the tibia even with delayed presentation. We do not recommend using unreamed nailing for type-III fractures with delayed presentation, because of the high incidence of complications, which may need revision procedures. 


\section{References}

1. Bach AW, Hansen Jr ST (1989) Plates versus external fixation in severe open tibial shaft fractures: a randomized trial. Clin Orthop 241:89-94

2. Bonatus T, Olson SA, Lee S, Chapman MW (1997) Non- reamed locking intramedullary nailing for open fractures of the tibia. Clin Orthop 339:58-64

3. Court-Brown CM, McQueen MM, Quaba AA, Christie J (1991) Locked intramedullary nailing of open tibial fractures. J Bone Joint Surg Br 73:959-964

4. Gustilo RB, Anderson JT (1976) Prevention of infection in the treatment of one-thousand and twenty-five open fractures oflong bones: retrospective and prospective analyses. J Bone Joint Surg Am 58:453-458

5. Hasenhuttl K (1981) The treatment of unstable fractures of the tibia and fibula with flexible medullary wires. A review of twohundred and thirty-five fractures. J Bone Joint Surg Am 63:921-931

6. Henley MB, Chapman JR, Agel J, Harvey J, Whorton AM, Swiontkowski MF (1998) Treatment of type II, IIIA, and IIIB open fractures of tibial shaft. A prospective comparison of unreamed interlocking intramedullary nails and half-pin external fixators. J Orthop Trauma 12:1-7

7. Holbrook JL, Swiontkowski MF, Sanders R (1989) Treatment of open fractures of the tibial shaft: ender nailing versus exter- nal fixation. A randomized prospective comparison. J Bone Joint Surg Am 71:1231-1238

8. Klein MP, Rahn BA, Frigg R, Kessler S, Perren SM (1989) Reaming versus non-reaming in medullary nailing: inter- ference with cortical circulation of the canine tibia. Arch Orthop Trauma Surg 109:314-316

9. Klemm KW, Borner M (1986) Interlocking nailing of complex fractures of the femur and tibia. Clin Orthop 212:89-100

10. Lottes JO (1974) Medullary nailing of the tibia with triflange nail. Clin Orthop 105:53-66

11. Melcher GA, Metzdorf A, Schegel U, Ziegler WJ, Perren SM, Printzen G (1995) Influence of reaming versus nonreaming in intramedullary nailing on local infection rate: experimental investigation in rabbits. J Trauma 39:1123-1128

12. Schandelmaier P, Krettek C, RudolfJ, Kohl A, Katz BE, Tscherne $H$ (1997) Superior results of tibial rodding versus ex- ternal fixation in grade 3B fractures. Clin Orthop 342:164-172

13. Stegemann P, Lorio M, Soriano R, Bone L (1995) Manage- ment protocol for unreamed interlocking tibial nails for open tibial fractures.J Orthop Trauma 9:117-120

14. Tornetta P 3rd, Bergman M, Watnik N, Berlowitz G, Steuer J (1994) Treatment of grade-IIIb open tibial fractures. A prospective randomised comparison of external fixation and nonreamed locked nailing.J Bone Joint Surg Br 76:13-19

15. Whittle AP, Russel TA, Taylor JC, Lavelle DG (1992) Treatment of open fractures of the tibial shaft with the use of interlocking nailing without reaming. J Bone Joint Surg Am 74:1162-1171

16. KneifelT, Buckley R. A comparison of one versus two distal locking screws in tibial fractures treated with unreamed tibial nails: a prospective randomized clinical trial. Injury 1996;27:271-3.
Conflict of Interest: NIL Source of Support: NIL
How to Cite this Article

Mohapatra N, Sahoo U S. | Open fractures of tibia treated by unreamed interlocking nailing. |Odisha Journal of Orthopaedics \& Trauma | Jan-June 2020; 41(1):3-6. 